\title{
Tamanho de sementes e fertilizante de liberação controlada na produção de mudas de Schizolobium parahyba [(Vell.) S. F. Blake)]
}

\author{
João Alexandre Lopes Dranski * \\ Eduarda Thais Sonda \\ Jeferson Carlos Demarchi Junior \\ Faculdade Educacional de Medianeira - UDC Medianeira \\ Rua Rio Branco, 1.820, CEP 85.884-000, Medianeira - PR, Brasil \\ * Autor para correspondência \\ joaodranski@yahoo.com.br
}

Submetido em 13/11/2018

Aceito para publicação em 13/02/2019

\section{Resumo}

Este trabalho testou a influência do tamanho da semente e de doses de fertilizante de liberação controlada na emergência e no crescimento de mudas de Schizolobium parahyba. As sementes foram previamente classificadas em três intervalos de classes com base no comprimento da semente: pequenas, médias e grandes. A semeadura ocorreu em tubetes de $120 \mathrm{~cm}^{3}$ preenchidos com substrato comercial e fertilizados com 3,5 e 8 g. $\mathrm{L}^{-1}$ de fertilizante de liberação controlada. Aos sete e 21 dias da semeadura, determinaram-se a porcentagem de emergência e o vigor das mudas, respectivamente. O tempo de crescimento das mudas foi de 18 semanas após a semeadura. Ao final, foram mensurados os parâmetros de qualidade das mudas. Sementes pequenas tiveram menor velocidade e porcentagem de emergência, enquanto sementes classificadas como médias e grandes não diferiram significativamente entre si. Caso haja classificação de sementes de S. parahyba, a dose de fertilizante deverá ser planejada de acordo com o tamanho da semente, do contrário uma dose de $5 \mathrm{~g} . \mathrm{L}^{-1}$ promoverá uma uniformidade no tamanho, com o ônus de perda de potencial de crescimento e de qualidade de mudas oriundas de sementes de maiores dimensões.

Palavras-chave: Classificação de sementes; Estabelecimento de mudas; Fertilização de mudas; Guapuruvu

\section{Abstract}

Seed size and controlled-release fertilizer in the production of Schizolobium parahyba ((Vell.) S.F. Blake)) seedlings. This work tested the influence of seed size and controlled-release fertilizer doses on the emergence and growth of Schizolobium parahyba seedlings. Seeds were classified into three class intervals based on seed length: small, medium and large. Sowing occurred in $120 \mathrm{~cm}^{3}$ tubes filled with commercial substrate and 3, 5 and 8 g.L $\mathrm{L}^{-1}$ of controlled-release fertilizer. At 7 and 21 days of sowing, the emergence percentage and vigor of the seedlings was determined, respectively. Seedling growth time was 18 weeks after sowing. At the end, seedling quality parameters were measured. Small seeds had a lower emergence speed and emergence percentage, while seeds classified as medium and large did not differ significantly. If the S. parahyba seeds are classified, the fertilizer dose should be based on seed size. Otherwise, a dose of 5 g.L $\mathrm{L}^{-1}$ will promote uniformity in size, with a potential loss in quality and growth of seedlings from larger seeds.

Key words: Brazilian fern tree; Seed classification; Seedling establishment; Seedling fertilizer 


\section{Introdução}

A variabilidade no tamanho e no peso de sementes supre necessidades exigidas para a dispersão (sementes pequenas) e supre demandas para o estabelecimento de mudas (sementes grandes) (MALAVASI; MALAVASI, 2001). A quantidade de reservas das sementes está diretamente associada à morfologia funcional dos cotilédones, que afeta de forma significativa a germinação, o estabelecimento e o desenvolvimento das mudas, pois as reservas armazenadas na semente devem nutrir o crescimento da plântula até ela se tornar autotrófica (BEWLEY et al., 2013).

O crescimento inicial de mudas não depende apenas do potencial de desempenho inerente da semente, ou seja, o vigor, mas também das condições ambientais e edáficas de cultivo que possibilitem a expressão daquele potencial (GROSSNICKLE, 2012). A fertilização é um dos componentes críticos para a produção de mudas com qualidade, visto que as mudas depreciam rapidamente os nutrientes armazenados nos tecidos de reserva. Para alcançar taxas de crescimento desejado, as mudas devem contar com absorção de nutrientes disponibilizados a partir do substrato para manter em equilíbrio os processos fisiológicos, do contrário o crescimento é retardado e o vigor da muda não será expresso (JACOBS; LANDIS, 2009).

Entre as técnicas de fertilização em viveiros florestais, o emprego de fertilizantes de liberação controlada (FLC) representa uma das mais viáveis e racionais alternativas. Apesar de possuírem um custo superior em relação às fontes de fertilizantes comerciais tradicionais, requerem menor quantidade de fertilizantes durante o ciclo de produção da muda, bem como reduzem ou mesmo eliminam a adubação de cobertura no viveiro (ROSSA et al., 2013).

Diversas pesquisas reportaram que sementes de maiores dimensões efetivamente originam mudas de maior tamanho, a exemplo do observado por Antunes et al. (2012) em sementes de Eugenia uniflora L. e por Pagliarini et al. (2014) em sementes de Hymeneae courbaril L., enquanto mudas produzidas com sementes de menores dimensões dessas espécies geraram mudas com tamanho e qualidade inferior.
A manutenção do vigor das mudas oriundas de sementes de maiores dimensões é dependente de doses mais elevadas de fertilização a fim de se obter a máxima expressão de seu vigor. Por outro lado, se sementes com menores dimensões e peso são desprovidas de abundância em substâncias de reservas, o manejo da fertilização no viveiro pode suprir esse déficit, resultando em mudas de tamanho e qualidade semelhante às originadas de sementes de maiores dimensões.

A espécie $S$. parahyba pertence à Fabaceae, nativa da Mata Atlântica, com ocorrência espontânea nas diversas formações florestais desse bioma (CARVALHO, 2005), a exemplo da Floresta Estacional Semidecidual no Oeste do Paraná (MARCON et al., 2013). É uma espécie de rápido crescimento, seletiva higrófita, ocupando principalmente planícies aluviais, ao longo de rios e no início de encostas (CARVALHO, 2005). A madeira pode ser empregada para produção de painéis de aglomerados de três camadas (TRIANOSKI et al., 2011), bem como para reflorestamento de áreas degradadas (RESENDE; PINTO, 2013; GONZALO et al., 2015).

Este trabalho objetivou testar a influência do tamanho da semente e das doses de fertilizante de liberação controlada na emergência e no crescimento de mudas de $S$. parahyba.

\section{Material e Métodos}

O experimento foi instalado em ambiente protegido localizado na Faculdade Educacional de Medianeira, Medianeira-PR, durante os meses de setembro a dezembro de 2016. A temperatura média do ambiente propagativo manteve-se a $29,0 \pm 5,0^{\circ} \mathrm{C}$ com umidade relativa do ar de $72,0 \pm 14,0 \%$.

Sementes de $S$. parahyba foram coletadas em agosto de 2016, a partir de três árvores matrizes, situadas em uma área de mata ciliar na região do município de Medianeira-PR, sob coordenadas geográficas de $25^{\circ} 17^{\prime} 37,9^{\prime \prime} \mathrm{S}$ e $54^{\circ} 07^{\prime} 09,5^{\prime \prime} \mathrm{O}$, com altitude de 387 $\mathrm{m}$. As matrizes estavam distanciadas entre si por pelo menos $100 \mathrm{~m}$. 


\section{Classificação}

As sementes foram extraídas dos frutos com endocarpo predominantemente marrom, papiráceo e desprendido do pericarpo (PIETROBOM et al., 2004). Após a coleta, as sementes foram extraídas manualmente do endocarpo, homogeneizadas, imersas em solução de hipoclorito de sódio a $0,5 \%$ por 5 min e postas para secagem à sombra por sete dias.

\section{Morfometria, grau de umidade e peso de matéria seca}

Três mil sementes foram classificadas em três intervalos de classes com base no comprimento da semente (medido perpendicularmente a micrópila), sendo então denominadas de sementes pequenas, médias e grandes.

Após a classificação, foram mensuradas em quatro repetições de 50 sementes por classe, o comprimento (medido perpendicularmente à micrópila), a largura (medida na região mediana adjacente à micrópila) e a espessura (medida direta de face a face). O grau de umidade foi determinado pelo método de secagem em estufa por $24 \mathrm{~h}$ a $105 \pm 3^{\circ} \mathrm{C}$ (BRASIL, 2009), em quatro repetições de 25 sementes. Obteve-se, assim como a determinação do grau de umidade, a massa da matéria seca (MS) de 25 sementes por repetição.

\section{Semeadura}

A semeadura ocorreu em setembro de 2016, em quatro repetições de 25 sementes, em tubetes de seção circular e volume de $120 \mathrm{~cm}^{3}$, preenchidos com substrato comercial à base de casca de pinus e acomodados em bandejas plásticas com capacidade para 96 recipientes. A fertilização foi feita com 3,5 e 8 g. $\mathrm{L}^{-1}$ de fertilizante de liberação controlada (Osmocote ${ }^{\circledR}$ Classic 3-4 meses), de formulação $\mathrm{N}_{2}-\mathrm{P}_{2} \mathrm{O}_{5}-\mathrm{K}_{2} \mathrm{O}$ (14-14-14), incorporado ao substrato, o que representa 360, 600 e $960 \mathrm{mg}$ de FLC por tubete, para cada dose, respectivamente. Antevendo a semeadura, as sementes foram imersas em água aquecida a $100^{\circ} \mathrm{C}$ e, imediatamente, foi desligada a fonte de calor e as sementes permaneceram na água por $2 \mathrm{~min}$ (MATHEUS; LOPES, 2007).

\section{Tempo de crescimento}

O tempo de crescimento das mudas foi de 18 semanas após a semeadura. Esse período foi determinado com base na altura-alvo de $30 \mathrm{~cm}$, independentemente do tratamento. Após três semanas da semeadura, realizouse a redução pela metade da ocupação dos tubetes nas bandejas de plástico. As mudas foram irrigadas diariamente às $18 \mathrm{~h}$ por aspersão, com lâmina de $14 \mathrm{~mm}$ durante $20 \mathrm{~min}$.

A porcentagem de emergência de plântulas normais em primeira contagem (após sete dias da semeadura) e a porcentagem de emergência de plântulas normais após 21 dias (emergência) foram quantificadas, seguindo a recomendação das instruções para análise de sementes de espécies florestais (BRASIL, 2013).

Ao término das 18 semanas, em cinco mudas por repetição (quatro repetições), foram mensurados o comprimento do hipocótilo $(\mathrm{cm})$, a altura da parte aérea $(\mathrm{H})(\mathrm{cm})$, o diâmetro do coleto (D) (mm) e foi calculada a relação entre a altura e o diâmetro do coleto (relação H/D). A área foliar foi obtida pelo método de discos foliares e quantificadas a massa seca de raiz (MSR) e a massa seca dos tecidos aéreos (MSPA) por meio do método de secagem em estufa por $72 \mathrm{~h} \mathrm{a} 65^{\circ} \mathrm{C}$, sendo os resultados expressos em g por muda, além da soma de ambos os componentes (MSPA + MSR), representando a massa seca total (MST), expresso em g por muda. Complementarmente foi calculado o índice de qualidade de Dickson (IQD) (DICKSON et al., 1960), conforme a Equação: IQD = [MST / (H/D) + (MSPA/MSR $)]$.

\section{Delineamento experimental}

O experimento foi conduzido em delineamento inteiramente ao acaso em arranjo bifatorial ( $3 \times 3$ ) composto por três classes quanto ao tamanho da semente: pequena $(P)$, média $(M)$ e grande $(G)$ e por três doses de fertilizantes de liberação controlada $\left(3,5\right.$ e 8 g.L.- $\left.{ }^{-1}\right)$, com quatro repetições.

\section{Análise dos dados}

Os dados foram averiguados quanto à normalidade da distribuição dos resíduos pelo teste de Lilliefors 
e quanto à homogeneidade da variância pelo teste de Cochran. Posteriormente, os dados foram submetidos à análise de variância com o auxílio do software SigmaPlot 12.0 (SIGMAPLOT, 2011). Quando da existência de diferenças estatisticamente significativas, as médias foram comparadas pelo teste de Tukey a $5 \%$ de probabilidade de erro. Os coeficientes de correlação simples de Pearson entre as variáveis a 5\% de probabilidade de erro pelo teste $\mathrm{t}$ foram calculados.

\section{Resultados}

A amplitude do intervalo de classe, com base no comprimento das sementes, foi de $2 \mathrm{~cm}$, sendo que a amplitude total foi de $6,06 \mathrm{~mm}$, e o menor comprimento foi de $26,27 \mathrm{~mm}$. Com isso, foi possível obter uma frequência relativa de $35,8 \%, 33,4 \%$ e $30,8 \%$ para sementes classificadas como pequenas $(\mathrm{P})$, médias $(\mathrm{M})$ e grandes $(\mathrm{G})$, respectivamente.

Sementes $\mathrm{P}$ tiveram massa seca $27 \%$ inferior à das sementes G (Tabela 1). Em sementes $\mathrm{M}$, a diferença foi de $16 \%$. Com relação à morfometria das sementes, sementes $\mathrm{P}$ tiveram tamanho inferior de $13 \%, 9 \%$ e $11 \%$ em comparação com sementes $\mathrm{G}$, para medidas de comprimento, largura e espessura (respectivamente). Para sementes M, o tamanho foi de $6 \%, 5 \%$ e $4 \%$ inferior em relação às sementes $\mathrm{G}$, para os mesmos atributos, respectivamente. $\mathrm{O}$ grau de umidade não diferiu significativamente entre as classes de tamanho, com média de $8,7 \%$.
Todas as variáveis avaliadas após a semeadura apresentaram distribuição normal dos resíduos e homogeneidade das variâncias a 5\% de probabilidade de erro. A análise de variância revelou não haver efeito de interação entre os fatores avaliados para a porcentagem de emergência em primeira contagem $(F=1,127$; $p=0,36)$, em contagem final $(F=0,297 ; p=0,877) e$ para o comprimento do hipocótilo $(F=2,352 ; p=0,079)$. Para essas variáveis, houve evidências de diferenças significativas para o tamanho da semente $(\mathrm{p}<0,05)$.

Sementes classificadas como $\mathrm{P}$ apresentaram menor porcentagem de emergência de mudas (Figura 1) e também menor velocidade de emergência, expressos pelos resultados da primeira contagem de emergência, enquanto sementes classificadas como $M$ e $G$ não diferiram significativamente entre si.

A porcentagem de emergência no $21^{\circ}$ dia após a semeadura foi de $46 \%$ para sementes $\mathrm{M}$ e $\mathrm{G}$, enquanto a das sementes de menores dimensões $(\mathrm{P})$ foi de $22 \%$. A porcentagem de emergência em primeira contagem foi em média de $25 \%$ para sementes $\mathrm{M}$ e $\mathrm{G}$ e de $10 \%$ para sementes P. Ressalta-se que após 21 dias da semeadura ainda houve emergência de plântulas para todas as classes, mas estas não foram utilizadas na pesquisa na tentativa de minimizar discrepâncias de tamanho da muda.

O comprimento do hipocótilo foi significativamente maior para mudas oriundas de sementes G (Figura 1), cujo comprimento de hipocótilo foi $59 \%$ maior em

TABELA 1: Massa seca de sementes (MS), grau de umidade (GU), comprimento (C), largura (L) e espessura (E) de sementes de $S$. parahyba classificadas como pequenas, médias e grandes.

\begin{tabular}{cccc}
\hline & \multicolumn{3}{c}{ Tamanho da semente } \\
\cline { 2 - 4 } Variáveis & Pequena $(\mathbf{P})$ & Média $(\mathbf{M})$ & Grande $(\mathbf{G})$ \\
\cline { 2 - 4 } & $\mathbf{2 6 , 3 0 - 2 8 , 3 0}$ & $\mathbf{2 8 , 3 0 - 3 0 , 3 0}$ & $\mathbf{3 0 , 3 0 - 3 2 , 3 0}$ \\
\hline MS $\left(\mathrm{g}^{-1}\right)$ & $1,44 \pm 0,02 \mathrm{c}$ & $1,65 \pm 0,02 \mathrm{~b} \pm 0,01 \mathrm{a}$ \\
GU $(\%)$ & $8,69 \pm 0,04 \mathrm{a}$ & $8,74 \pm 0,06 \mathrm{a}$ & $8,71 \pm 0,08 \mathrm{a}$ \\
C $(\mathrm{mm})$ & $26,96 \pm 0,05 \mathrm{c}$ & $29,06 \pm 0,06 \mathrm{~b}$ & $30,85 \pm 0,03 \mathrm{a}$ \\
$\mathrm{L}(\mathrm{mm})$ & $16,56 \pm 0,08 \mathrm{c}$ & $17,14 \pm 0,13 \mathrm{~b}$ & $18,13 \pm 0,07 \mathrm{a}$ \\
E $(\mathrm{mm})$ & $3,92 \pm 0,04 \mathrm{c}$ & $4,25 \pm 0,05 \mathrm{~b}$ & $4,40 \pm 0,07 \mathrm{a}$ \\
\hline
\end{tabular}

Médias seguidas de mesma letra minúscula na linha não diferem significativamente entre si pelo teste de Tukey ao nível de $5 \%$ de probabilidade de erro. 
comparação ao mensurado em mudas oriundas de sementes P. Mudas originadas de sementes M tiveram o comprimento de hipocótilo $32 \%$ maior em relação ao das mudas oriundas de sementes $\mathrm{P}$ e $17 \%$ menor em relação ao das mudas provenientes de sementes $\mathrm{G}$.

Todas as plântulas emergidas sobreviveram até o final do período avaliativo (18 semanas). De acordo com a Figura 2A (tratamento 3 g. $\mathrm{L}^{-1}$ ), nota-se uma diferença significativa na altura de mudas oriundas de sementes $\mathrm{P}$ em relação somente às mudas oriundas de sementes $M$. Não há diferenças estatísticas significativas em relação às mudas de sementes $\mathrm{G}$. As avaliações de diâmetro do coleto (Figura 2B) e de área foliar (Figura 2D) não apresentam diferenças estatísticas significativas. A relação $\mathrm{H} / \mathrm{D}$ foi maior para sementes de tamanho médio (Figura 2C).

Mudas originadas de sementes M e G responderam positivamente no crescimento aéreo com o incremento da fertilização, ao passo que sementes de tamanho $\mathrm{M}$, a dose de 8 g.L $L^{-1}$, reduziram em área foliar (Figura 2D).
As doses de FLC com até 5 g.L $\mathrm{L}^{-1}$ não afetaram o acúmulo de matéria seca total (MST) (Figura 3A) nem seus componentes radicular (MSR) (Figura 3B) e aéreo (MSPA) (Figura 3C) para mudas originadas de sementes $\mathrm{P}$; porém, a dose de 8 g. $\mathrm{L}^{-1}$ reduziu o acúmulo de biomassa abaixo do obtido com a menor dose de FLC, haja vista que nessa dose houve uma redução na área foliar, o que impacta negativamente a atividade fotossintética e consequentemente no acúmulo de biomassa nos componentes aéreo e radicular. Corroborando o exposto, houve uma correlação significativa diretamente proporcional com coeficiente de $0,86(p<0,01)$ entre os componentes de área foliar e o acúmulo de matéria seca total.

De acordo com a Figura 3A, o aumento da dose de FLC 5 g.L. - $^{-1}$ para 8 g.L. - $^{-1}$ não gerou diferença significativa na MST em sementes M, apenas entre as sementes G. Para a MSR (Figura 3B), a diferença estatística significativa se dá apenas entre as sementes M. Para a MSPA, apenas entre as sementes G (Figura 3C), ou seja, em mudas originadas de sementes $\mathrm{M}$ e $\mathrm{G}$, com o

FIGURA 1: Efeito do tamanho das sementes sobre a porcentagem de emergência de plântulas em primeira e última contagem (emergência) e no comprimento do hipocótilo de mudas de $S$. parahyba. Barras verticais representam a diferença mínima significativa (DMS) pelo teste de Tukey ao nível de 5\% de probabilidade de erro. Em que $\mathrm{P}, \mathrm{M}$ e G referem-se às sementes classificadas como pequenas, médias ou grandes. Letras minúsculas quando iguais não indicam variações intragrupo pelo teste de Tukey ao nível de $5 \%$ de probabilidade de erro.

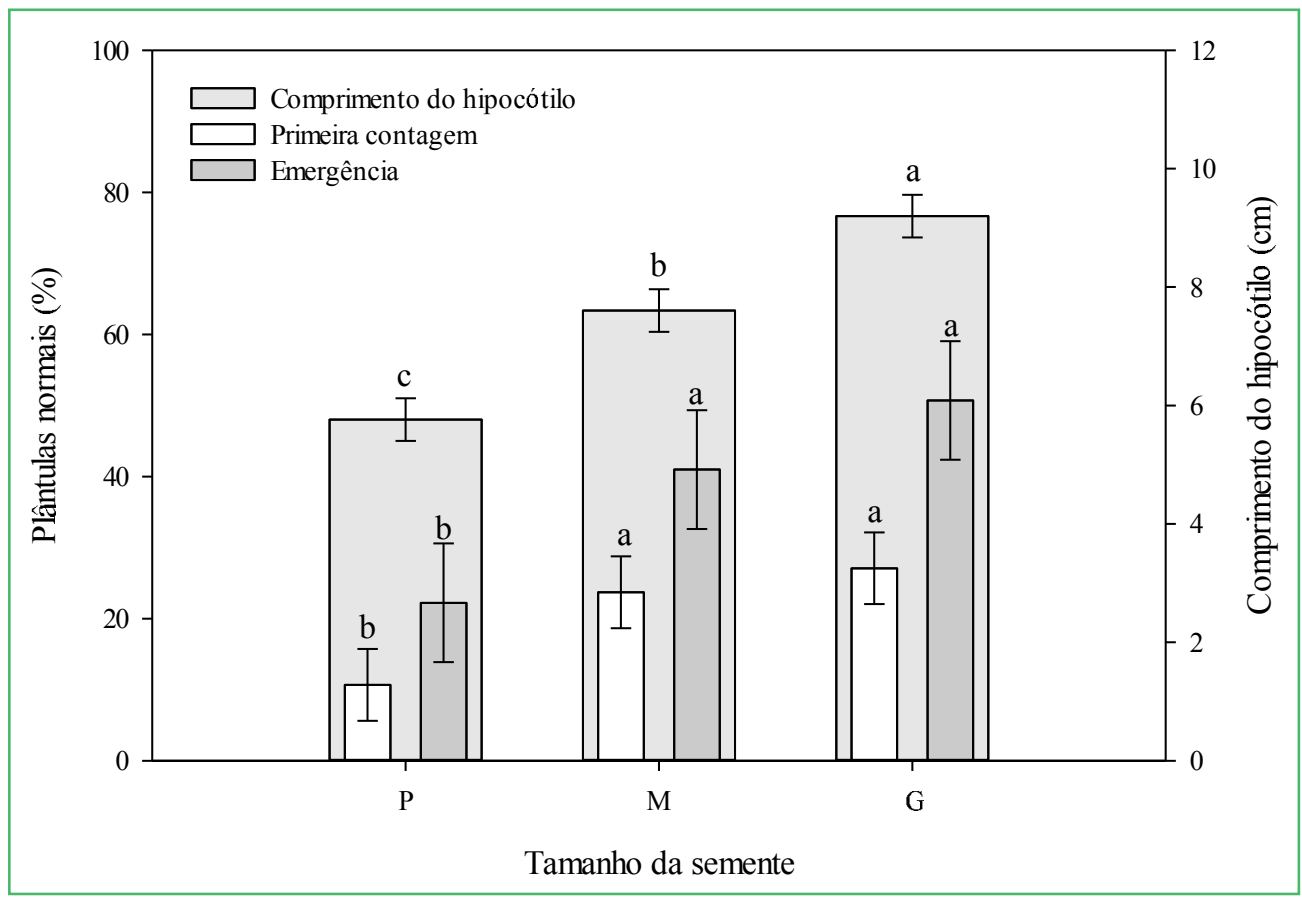


FIGURA 2: Efeito do tamanho das sementes e doses de FLC no crescimento de mudas de S. parahyba. (A) Altura (H); (B) diâmetro do coleto (D); (C) relação H/D; (D) área foliar. Barras verticais representam a diferença mínima significativa (DMS) pelo teste de Tukey ao nível de $5 \%$ de probabilidade de erro. Em que $\mathrm{P}, \mathrm{M}$ e $\mathrm{G}$ referem-se às sementes classificadas como pequenas, médias ou grandes. Letras minúsculas quando iguais não indicam variações intragrupo e maiúsculas quando iguais não indicam variações intergrupo pelo teste de Tukey ao nível de $5 \%$ de probabilidade de erro.

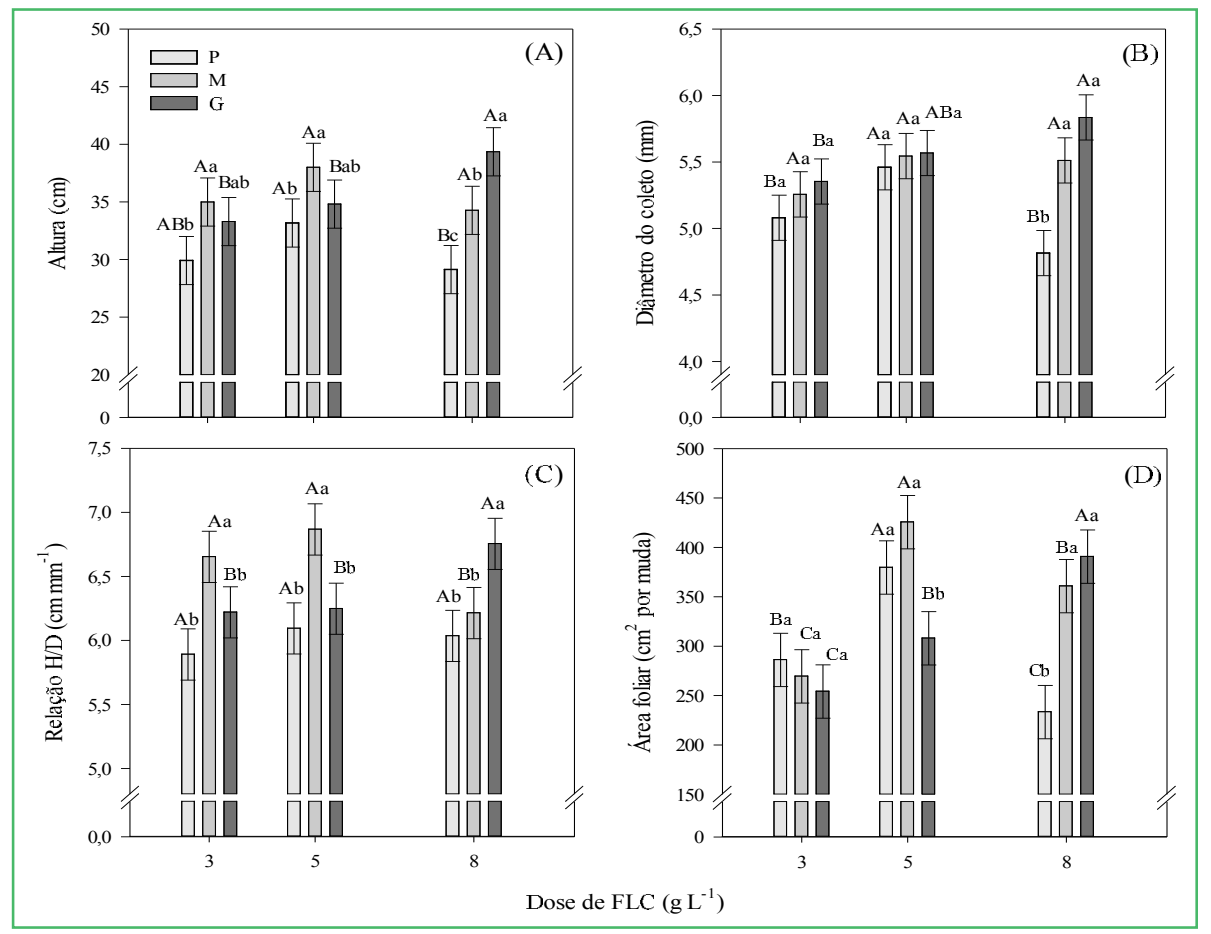

FIGURA 3: Efeito do tamanho das sementes e doses de fertilizante de liberação controlada (FLC) no crescimento de mudas de $S$. parahyba. (A) massa seca total; (B) massa seca dos tecidos radiculares; (C) massa seca dos tecidos aéreos; (D) índice de qualidade de Dickson (IQD). Barras verticais representam a diferença mínima significativa (DMS) pelo teste de Tukey ao nível de 5\% de probabilidade de erro. Em que $\mathrm{P}, \mathrm{M}$ e $\mathrm{G}$ referem-se às sementes classificadas como pequenas, médias ou grandes. Letras minúsculas quando iguais não indicam variações intragrupo e maiúsculas quando iguais não indicam variações intergrupo pelo teste de Tukey ao nível de 5\% de probabilidade de erro.

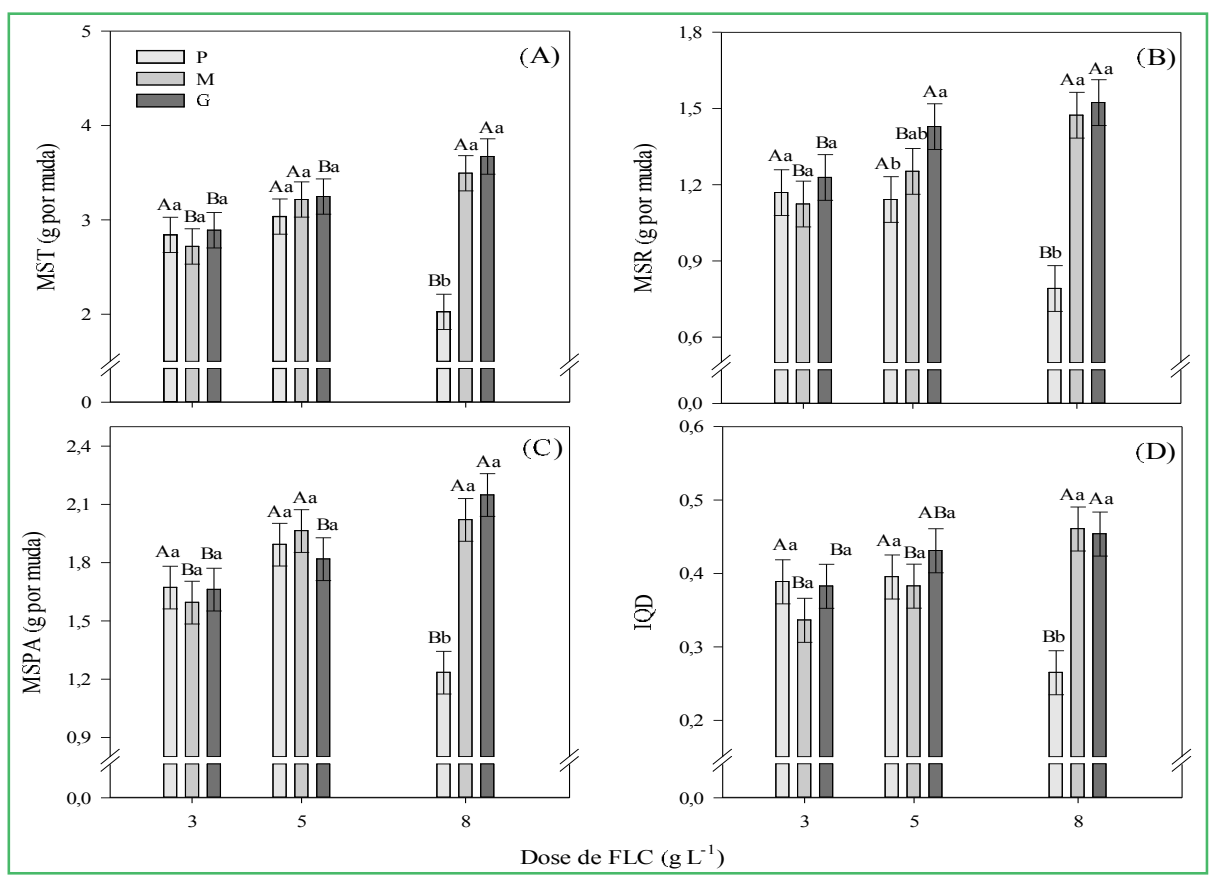


aumento da dose de FLC, houve aumento no acúmulo de biomassa de seus componentes. Para sementes M, a dose de 8 g.L. $\mathrm{L}^{-1}$ promoveu um maior acúmulo de biomassa no sistema radicular, ao passo que para sementes $G$, nessa dose, houve um maior acúmulo de biomassa nos tecidos aéreos, haja vista que o crescimento morfométrico aéreo foi maior (Figura 2).

O Índice de Qualidade de Dickson (Figura 3D) não acusou diferenças para o tamanho da semente até a dose

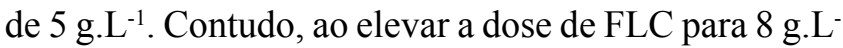
1 , mudas originadas de sementes $\mathrm{M}$ e $\mathrm{G}$ manifestaram seu potencial fisiológico aumentando o IQD em $18 \%$ e $28 \%$, respectivamente, quando comparado ao obtido com 3 g.L L $^{-1}$. Para sementes classificadas como P, o IQD foi reduzido em $32 \%$.

\section{Discussão}

A ausência de efeitos significativos da incorporação do fertilizante de liberação controlada sobre a germinação era esperada, uma vez que as mudas nos estágios iniciais de desenvolvimento são dependentes da remobilização de reservas acumuladas durante a maturação, e a necessidade de suprimento nutricional inicia a partir do momento em que ocorre a diferenciação do complexo estomático nas folhas cotiledonares e a atividade fotossintética é pronunciada em relação à atividade respiratória, momento este que marca a passagem do estado heterotrófico para autotrófico das mudas (ZHENG et al., 2011).

A velocidade de germinação mais rápida para sementes de menor tamanho não foi observada na presente pesquisa, conforme demonstraram os resultados obtidos para porcentagem de emergência em primeira contagem (Figura 1). Em geral, sementes de menores dimensões germinam mais rapidamente e isso proporciona uma vantagem competitiva para a colonização de habitat com estágios iniciais de sucessão, ao passo que as de maiores dimensões geram maior taxa de germinação para habitat mais previsíveis (SOUZA; FAGUNDES, 2014).

Para $S$. parahyba a velocidade e a porcentagem de emergência (Figura 1) foram maiores quanto maior foi o tamanho da semente. Isso revela a plasticidade fenotípica que a espécie possui, pois ocorre na floresta primária, na secundária e em clareiras florestais, sendo classificada como pioneira, secundária inicial ou clímax (CARVALHO, 2005). Portanto, sementes M e G seriam favorecidas pelo estabelecimento em habitat com baixa luminosidade, ao passo que as sementes menores, em ambientes de sucessão inicial.

Sementes M e G possuem um maior conteúdo de reservas, portanto, resultaram em maior desenvolvimento pós-seminal, conferindo maior vigor, como o observado na porcentagem de emergência em primeira contagem e no comprimento do hipocótilo (Figura 1). A capacidade de $S$. parahyba de remobilizar reservas para o crescimento embrionário está diretamente relacionada ao conteúdo nutricional materno alocado nas sementes durante a maturação, visto que Durda et al. (2007) não observaram diferenças significativas no teor de amido nos cotilédones e no teor de açúcares totais solúveis no eixo embrionário em função do tamanho das sementes da espécie.

O crescimento das mudas de S. parahyba é do tipo epígeo-fanerocotiledonar e esse modelo de crescimento embrionário está associado com a rápida colonização em sucessão ecológica (MENEZES et al., 2017). Portanto, o investimento em crescimento do hipocótilo de mudas originadas de sementes $\mathrm{M}$ e $\mathrm{G}$ indica que as mudas tornam-se melhores competidoras sob restrições de luminosidade e temperatura (PETRIE et al., 2016; CHMURA et al., 2017).

Macera et al. (2017) estudaram relações entre a massa da semente com a sobrevivência de nove espécies lenhosas nativas da família Fabaceae sob condições de restauração ambiental e constataram que sementes com maior massa tiveram uma taxa de sobrevivência maior, pois a maior remobilização de substâncias de reserva promoveu um maior crescimento do sistema radicular e aéreo, deixando as mudas com maior capacidade de absorção de água, nutrientes e luz, e, portanto, tornandoas melhores competidoras sob pressão interespecífica.

A baixa concentração de nutrientes disponibilizados pela dose de 3 g.L.- - $^{-1}$ afetou o crescimento primário e secundário, a área foliar (Figura 2) e consequentemente o acúmulo de biomassa (Figura 3) para mudas 
oriundas de sementes classificadas como M e G. Esse aporte reduzido de nutrientes resultou em mudas com qualidade inferior, visto que com a dose de 8 g.L $\mathrm{L}^{-1}$ de FLC o IQD foi significativamente maior (Figura 3D). Esses resultados corroboram os de Coneglian et al. (2016), que avaliaram o crescimento de mudas de $S$. parahyba em solo com limitação de nutrientes e observaram que há uma redução significativa no crescimento e no acúmulo de biomassa.

Para mudas provenientes de sementes $\mathrm{P}$ obterem uma taxa de crescimento aéreo compatível às de mudas oriundas de sementes $G$, necessitariam de uma dose de fertilizante de disponibilidade controlada de 5 g.L $\mathrm{L}^{-1}$ (Figura 2D). Porém, com o aumento da dose para 8 g.L $\mathrm{L}^{-1}$, houve indícios de fitotoxidade, haja vista uma inibição do crescimento aéreo (Figura 2D).

A hipótese da presente pesquisa pautava-se da ideia de que sementes com menor tamanho e acúmulo de substâncias de reserva poderiam ser beneficiadas por um maior aporte de fertilizante. Isso não foi ratificado, visto que a qualidade das mudas, mensurada pelo IQD, foi menor quando aplicado 8 g.L. L $^{-1}$ de FLC.

$\mathrm{O}$ requerimento nutricional das mudas originadas de sementes $M$ e $G$ foi maior visto que o IQD foi significativamente maior na dose de 8 g. $\mathrm{L}^{-1}$. Esses resultados corroboram Jacobs e Landis (2009), pois apesar de sementes com maiores dimensões possuírem maior conteúdo de reservas (Tabela 1), houve maior dispêndio, acarretando um maior aporte nutricional para manifestação do vigor da muda. A dose de 5 g.L. $\mathrm{L}^{-1}$ permitiu obter mudas com uniformidade e qualidade semelhante, independentemente do tamanho da semente, com perda de qualidade para mudas oriundas de sementes M e G (Figura 3D).

O IQD é um dos mais completos parâmetros para avaliação da qualidade de mudas florestais, pois em seu cálculo são considerados a robustez do caule (relação entre altura e diâmetro do coleto) e o equilíbrio da distribuição da biomassa na muda (biomassa total e partição da biomassa dos tecidos aéreos e radiculares), ponderando os resultados de vários parâmetros importantes empregados para avaliação da qualidade (GROSSNICKLE, 2012).
Complementarmente, as sementes de S. parahyba possuem morfometria compatível para separação por peneiras com crivos circulares e oblongos, isso possibilitaria realizar uma classificação quanto ao tamanho das sementes e um manejo da fertilização aplicada no viveiro mais assertivo quanto ao tamanho da semente, resultando em mudas com qualidade superior.

A partir dos resultados foi possível concluir que, se ocorrer classificação de sementes de $S$. parahyba de acordo com o tamanho, a dose de fertilizante utilizada na formação da muda deverá ser planejada, porém, se não ocorrer classificação das sementes, uma dose de 5 g. $\mathrm{L}^{-1}$ da formulação $\mathrm{N}_{2}-\mathrm{P}_{2} \mathrm{O}_{5}-\mathrm{K}_{2} \mathrm{O}$ (14-14-14) promoverá uma uniformidade no tamanho das mudas, com o ônus de perda de potencial de crescimento e de qualidade para mudas oriundas de sementes de maiores dimensões, que necessitam de uma dose de FLC de 8 g.L.-1 da formulação $\mathrm{N}_{2}-\mathrm{P}_{2} \mathrm{O}_{5}-\mathrm{K}_{2} \mathrm{O}$ (14-14-14) para manifestar seu potencial de crescimento.

\section{Referências}

ANTUNES, L. E. C.; PiCOlOtTO, L.; VignOlO, G. K.; GONCALVES, M. A. Influência do substrato, tamanho de sementes e maturação de frutos na formação de mudas de pitangueira. Revista Brasileira de Fruticultura, Jaboticabal, v. 34, n. 4, p. 1216-1223, 2012.

BEWLEY, J. D.; BRADFORD, K. J.; HILHORST, H. W. M.; NONOGAKI, H. Seeds: physiology of development, germination and dormancy. 3. ed. New York: Springer, 2013. 392 p.

BRASIL. Regras para análise de sementes. Brasília: MAPA/ ACS, 2009. 395 p.

BRASIL. Instruções para análise de sementes de espécies florestais. Brasília: MAPA/SDA/CGAL, 2013. 97 p.

CARVALHO, P. E. R. Guapuruvú. Colombo: Embrapa Florestas, 2005. 10 p. (Circular Técnica, 104).

CHMURA, J.; MODRZYŃSKI, J.; CHMIELARZ, P.; TJOELKER, M. G. Plasticity in seedling morphology, biomass allocation and physiology among ten temperate tree species in response to shade is related to shade tolerance and not leaf habit. Plant Biology, Freiburg, v. 19, n. 2, p. 172-182, 2017.

CONEGLIAN, A.; RIBEIRO, P. H. P.; MELO, B. S.; PEREIRA, R. F.; DORNELES JUNIOR, J. Initial growth of Schizolobium parahybae in Brazilian Cerrado soil under liming and mineral fertilization. Revista Brasileira de Engenharia Agrícola e Ambiental, Campina Grande, v. 20, n. 10, p. 908-912, 2016.

DICKSON, A.; LEAF, A. L.; HOSNER, J. F. Quality appraisal of white spruce and white pine seedling stock in nurseries. Forestry Chronicle, Mattawa, v. 36, p. 10-13, 1960. 
DURDA, F.; UHLMANN, A.; PESCADOR, R. Dosagem de carboidratos nas sementes de Shizolobium parahyba e Talauma ovata de acordo com o tamanho seminal. Revista Brasileira de Biociências, Porto Alegre, v. 5, n. 2, p. 465-467, 2007.

GONZALO, D. A. D.; GARCIA, R. J. F.; GOMES, E. P. C. Avaliação de área recuperada sobre cava de areia em São Paulo, SP, Brasil. Hoehnea, São Paulo, v. 42, n. 4, p. 695-701, 2015.

GROSSNICKLE, S. C. Why seedlings survive: influence of plant attributes. New Forests, Sydney, v. 43, n. 5, p. 711-718, 2012.

JACOBS, D. F.; LANDIS, T. D. Hardening. In: DUMROESE, R. K.; LUNA, T.; LANDIS, T. D. (Ed.). Nursery manual for native plants: guide for tribal nurseries. Vol. 1. Washington: United States Department of Agriculture, Forest Service, 2009. p. 217-228.

MACERA, L. G.; PEREIRA, S. R.; SOUZA, A. L. T. Survival and growth of tree seedlings as a function of seed size in a gallery forest under restoration. Acta Botanica Brasilica, Belo Horizonte, v. 31, n. 4, p. 539-545, 2017.

MALAVASI, U. C.; MALAVASI, M. M. Influência do tamanho e do peso da semente na germinação e no estabelecimento de espécies de diferentes estágios da sucessão vegetal. Floresta e Ambiente, Seropédica, v. 8, n. 1, p. 211-215, 2001

MARCON, T. R.; TEMPONI, L. G.; GRIS, D.; FORTES, A. M. T. Guia ilustrado de Leguminosae Juss. arbóreas do Corredor de Biodiversidade Santa Maria - PR. Biota Neotropica, Campinas, v. 13, n. 3, p. 350-373, 2013.

MATHEUS, M. T.; LOPES, J. C. Termoterapia em sementes de guapuruvú (Schyzolobium parahyba (Vell.) Blake). Revista Brasileira de Biociências, Porto Alegre, v. 5, n. 2, p. 330-332, 2007.

MENEZES, T. G. C.; RODAL, M. J. N.; LIMA, A. L. A.; LIMA, L. R.; PINTO, M. A. D. S. C.; MELO, A. L. Do seedling functional groups reflect ecological strategies of woody plant species in Caatinga? Acta Botanica Brasilica, Belo Horizonte, v. 31, n. 5, p. 1-8, 2017.

PAGLIARINI, M. K.; NASSER, M. D.; NASSER, F. A. C. M.; CAVICHIOLI, J. C.; CASTILHO, R. M. M. Influência do tamanho de sementes e substratos na germinação e biometria de plântulas de jatobá. Tecnologia \& Ciência Agropecuária, João Pessoa, v. 8 , n. 5 , p. $33-38,2014$.
PETRIE, M. D.; WILDEMAN, A. M.; BRADFORD, J. B.; HUBBARD, R. M.; LAUENROTH, W. K. A review of precipitation and temperature control on seedling emergence and establishment for ponderosa and lodgepole pine forest regeneration. Forest Ecology and Management, Amsterdam, v. 361, p. 328-338, 2016.

PIETROBOM, R. C. V.; OLIVEIRA, D. M. T. Morfoanatomia e ontogênese do pericarpo de Schizolobium parahyba (Vell.) Blake (Fabaceae, Caesalpinioideae). Revista Brasileira de Botânica, São Paulo, v. 27, n. 4, p. 767-779, 2004.

RESENDE, L. A.; PINTO, L. V. A. Emergência e desenvolvimento de espécies nativas em área degradada por disposição de resíduos sólidos urbanos. Revista Agrogeoambiental, Pouso Alegre, v. 5, n. 1, p. 37-48, 2013.

ROSSA, U. B.; ANGELO, A. C.; NOGUEIRA, A. C.; BOGNOLA, I. A.; POMIANOSKI, D. J. W.; SOARES, P. R. C.; BARROS, L. T. S. Fertilização de liberação lenta no crescimento de mudas de paricá em viveiro. Pesquisa Florestal Brasileira, Colombo, v. 33, n. 75 , p. 227-234, 2013.

SIGMAPLOT. Scientific Graphing Software: Version 12.0. San Rafael: Jandel Corporation, 2011.

SOUZA, M. L.; FAGUNDES, M. Seed size as key factor in germination and seedling development of Copaifera langsdorffii (Fabaceae). American Jou rnal of Plant Sciences, Hubei Province, v. 5 , n. 17 , p. $2566-2573,2014$.

TRIANOSKI, R.; IWAKIRI, S. MATOS, J. L. M.; PRATA, J. G. Avaliação de espécies alternativas de rápido crescimento para produção de painéis de madeira aglomerada de três camadas. Scientia Forestalis, Piracicaba, v. 39, n. 89, p. 97-104, 2011.

ZHENG, W.; WANG, P.; ZHANG. H. Z.; ZHOU, D. Photosynthetic characteristics of the cotyledon and first true leaf of castor (Ricinus communis L.). Australian Journal of Crop Science, Sydney, v. 5, n. 6 , p. 702-708, 2011 . 